\title{
Applied-Information Technology with Transmission Features of New Media on News Communication
}

\author{
Xiuhu Tan \\ Journalism Department, Chengdu Sport University, Chengdu, China \\ txhchinese@163.com
}

\begin{abstract}
With the growth and convergence of information technology, new media provides a foundation for the emergence and development of sport news communication. To identify the opportunities and challenges in fast growing new media, in this paper, we discuss several emerging topics including new feature, construction and interaction, and present a transmission model of new media. The proposed model is integrated with an accessible mechanism that improves the ability of analysis and understanding of people to sport news. According to the transmission model, we put forward some theoretical principles and analyze the application misunderstandings of communication theory in sport domain, and improve the accuracy of data. The test result shows that the model can obtains empirical support in the application analysis.
\end{abstract}

Keywords: Media Streaming, Communication, Transmission Features.

\section{Introduction}

The rapid development of information technology has accelerated the pace of human society from an industrial society to an information society. New media with microblogging and network television as the representatives have immediacy and interactivity and other advantages, not only having a strong impact on the socio-economic patterns, but also achieving the popularity of media tools, and are playing an increasingly important role in the field of communication [1]. In the new media age, more and more people get information through the phone and Internet and other means[2], new media completely break the communication pattern of traditional media and bring a great impact on the survival and development of traditional media, and sports news communication also faces challenges of new media [3].

\section{Characteristics of Sports News Communication in New Media Age}




\section{Timeliness of sports news communication}

Sports news has the feature of timeliness, and only by spreading the latest sports information, sports news has the value. To improve the timeliness of sports news communication, the mode of communication is the key. Advances in technology promote new media not to require complex editing and post-production and publishing, but to be able to disseminate real-time sports news, and fast propagation speed makes the sender and receiver virtually no difference, makes the publishing of sports news free from the geographical restrictions, and shortens the distance between the communicator and the audience, so as to achieve real-time sports news communication.

\section{Interactivity of sports news communication}

Interactivity of new media refers to achieve two-way interaction between information communicators and information receivers [4]. The one-way news communication mode of traditional media refers to convey sports information to the audience by the information communicator through traditional media, and the audience is passive receivers of information and lacks the speaking right of information. New media breaks the relationship between the traditional news media and the audience and changes fundamentally the role and status of sports information receivers to accept the information passively; sports news communication is no longer just one-way publishing and communication, and sports news receivers can express their opinions in real time and can discuss and exchange relevant information, to achieve the two-way exchange and interactive use of information. Meanwhile, the interactivity increases personalized and interactive communication and improves the efficiency of sports news communication.

\section{Mobility of sports news communication}

Traditional media information communication, publication or broadcast have fixed time and fixed information receiving modes [5-6]. Sports information receivers must be in a fixed time and fixed space to accept sports information through fixed ways. And competitive sports are often changing, prompting the public to have a strong desire for obtaining sports news anytime and anywhere. Development of wireless mobile technology, especially the widespread application of 3G technology, allows people to liberate from the limitations of time and space, and the public is able to know real-time dynamic news via mobile phones and other information receiving ends. The mobility of new media enables young people to get more sports news, understand sports information and watch HD sports broadcasting through mobile terminals.

\section{Personalization of sports news communication}

New media can provide point to point, point to many, many to point and many to many information communication services, to enable communicators to 
provide personalized services for different audiences. Meanwhile, the sports news receivers can be in accordance with their needs and preferences to customize professional personalized sports information services. In different sports information programs, sports information receivers can be in accordance with their needs to choose sports information and remove useless sports information.

\section{Multimedia of sports news communication}

New media can spread different types of information, such as video, audio, Flash animation, images and texts, and information communicators can either individually select a certain type of communication or mix different types of information to spread. Mew media mixes all advantages of traditional media, making the information receivers be able to select the information, to really achieve multimedia communication ways of sports news.

\section{Analysis on Existing Problems of New Media in Sport News Communication}

\section{New media sports news communication lacks effective supervision}

In the traditional media information communication process, information communicators are responsible for information selection, sorting, examination and processing and then publishing. New media breaks the one-way information communication of traditional media, making each traditional audience become communicators of information. Two-way information communication of new media makes the status of information receivers in traditional media improve, but also bringing information communication regulatory issues. On the one hand, the arrival of the new media age makes a large amount of information published every day, but regulatory audit techniques and methods of information do not synchronize and can not effectively monitor the release of information in real time; on the other hand, the abuse of the right to information communication makes anyone be able to spread information for a certain purpose. Some citizens lack moral standards and some news reporters lack professional ethnics, leading to spread and make false and vulgar news, which is particularly prominent in the field of sports news communication(Fig 1). 


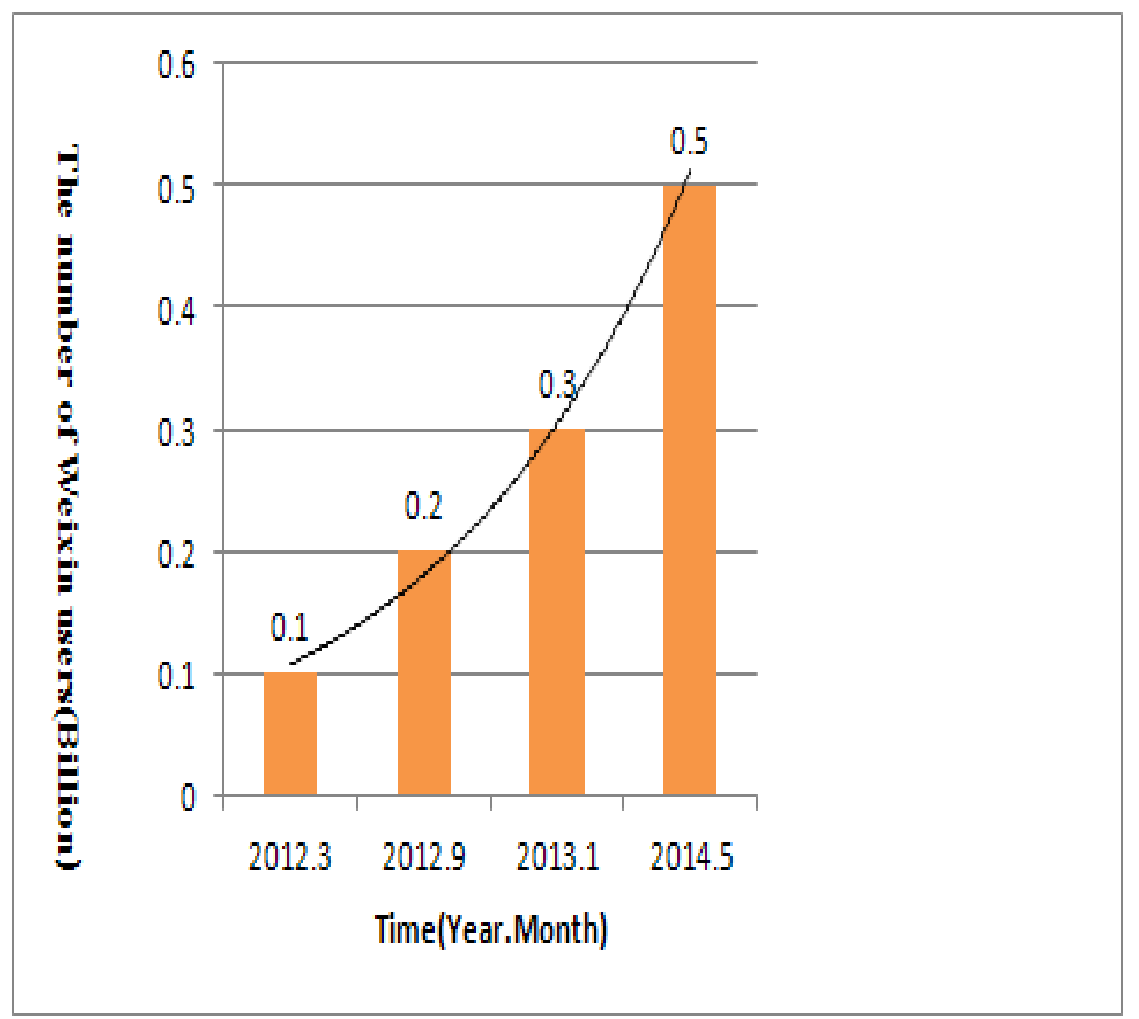

Fig 1 The Number of Weixin Users

\section{New media sports news communication lacks in-depth reports}

Sports news and comments published by new media are often extensive but not in-depth, lacking in-depth excavation of news of traditional media. At the same time, the regulatory mechanism and regulatory measures of information are not in place, and sports news and views published by new media lack the necessary supervision and audit, with randomness and not in-depth enough statement. This fast-food style sports news reports make the audience difficult to understand the nature of sports news. However, sports audiences are no longer satisfied with this simple way to obtain information, but want to understand the deeper meaning, the development process and the nature of sports news. Meanwhile, the audience can become the publishers of sports information in the new media information communication, and can publish sports information, which leads to the existence of inherent shortage of sports new media in terms of the authority of news release, as well as the lack of media authority of published sports news.

\section{New media sports news communication is excessively entertainment-oriented}


Sports news excessive entertainment means that in sports news communication process, the focus of news reports is not sports events itself, but to report some information unrelated to sporting events by the use of excessive packaging, lace and privacy means, such as lace news and anecdotes of athletes, interfering with the normal information access of people. For example, when some sites report NBA Jeremy Lin, the reports should focus on the basketball games and training and other aspects related to Jeremy Lin, but in fact, put the focus on Lin's private life, deviating from the nature of sports news reports. The sports news communication will come to entertainment news, which is understandable, but it is necessary to have a proper grasp of entertainment news.

\section{New media sports news communication lacks boutique sports columns or personalized brands}

The essence of brands is to distinguish different products or service names, logos, symbols, etc., and the brand is the product of competition. The boutique sports columns can improve the core competitiveness of the media and bring sustained social attention and stable audience loyalty for the media, which is fundamental to improve the media influence. However, except for a few number of large sports news media organizations, the vast majority of new media lacks featured diversification reports or lacks in-depth reports in the sports news release process, resulting in sports news of different media organizations to appear similar phenomenon.

\section{Sport News Media Communication Strategies in New Media Era}

\section{Strengthen the supervision of new media sports news communication}

In terms of new media sports news communication and advocacy regulation, governments, media organizations and the general sports audience have a dynamic game between each other, and the game process ultimately determines the system selection and institutional change between the communication and supervision of new media sports news. News supervision and management departments at all levels should continue to accelerate the construction of the relevant laws, regulations and administrative agencies, designedly strengthen the professional training of relevant personnel and improve their professional services as soon as possible.

Increase the in-depth reports of new media sports news communication

New media sports news contents should be increased the depth, highlighting the spirit taste of sports news. In today's fiercely competitive media era, facing the colorful new media sports news, sports audience usually uses the heading type of reading way, difficult to understand the nature of sports news. The in-depth report of sports news communication is to interpret the relation between sports competitions and game data and results as well as the analysis of the turning point 
of games for audience, making the audience understand the news behind the sports news and get to the nature of sports news.

\section{Improve the comprehensive quality of practitioners of new media sports news communication}

The core strength of sports news communication development is highly qualified practitioners. New media sports news communication practitioners not only need to have the basic quality of traditional news media workers, but also need to have the ability of new media applications, be familiar with the sports news communication features and understand the latest development trends of the spread field. Without sports news communication and relevant knowledge reserves and cultural qualities, sports news media workers can not be engaged in the practice of sports news communication.

\section{Adhere to the authenticity of new media sports news communication}

In new media age, sports audience can also release information, with many valuable news clues and a lot of false news. The public opinion misleading resulting from false news published by these sports audience is not conducive to the healthy development of sports, and is the biggest challenge to the authority and credibility of the sports news media, and also results in the lack of sports values. Authenticity is the life of news, so sports news communication must adhere to the authenticity.

\section{Conclusion}

For the construction and development of sports career, sports news communication plays an important supporting role. New media not only brings new opportunities for the development of sports news communication career, but also poses new challenges for the sports news communication. We should strengthen own management, not only pursuing economic efficiency, but also pursuing social values in the sports news communication, so as to promote the standardization of sports news communication in new media age

\section{References}

[1] Liang. Z, Haohong .W: IEEE Trans, Multimedia. Vol. 15(4) (2013), p. 735.

[2] Sha. X Wang. D: IEEE Trans, Multimedia. Vol. 15(4) (2013), p. 870.

[3] Shaolei. R, Vander. SM: IEEE Trans, Multimedia. Vol.15(4) (2013), p. 723.

[4] Ali. T, Saquib. M: IEEE Trans, Digital Object Identifier. Vol. 12(3) (2013), p. 447. 
[5] Xiong. S, Bogy: IEEE Trans, Magnetics. Vol. 50(3) (2014), p. 102.

[6] Maes. R, Schellekens. D: IEEE Trans, Information Forensics and Security. Vol. 7(1) (2012), p. 98. 